\title{
Exploring Language Teachers' Beliefs About the Medium of Instruction and Actual Practices Using Complex Dynamic System Theory
}

\author{
Yang Gao * and Yafang Zhou \\ English Department, School of Foreign Languages, Dalian Maritime University, Dalian, China
}

This paper explores the relations between teacher beliefs and practices about the medium of instruction from the perspective of complex dynamic systems theory. Through a functional framework of teacher classroom discourse, mixed analytical models were adopted to fully describe the close interaction and non-linear relations between teacher beliefs and practices. Data were collected through classroom observations and semi-structured interviews from three college teachers working in a typical research-based university in northeast China. The findings revealed the complex and dynamic relations between teacher beliefs and practices about the medium of instruction. The consistency and inconsistency between the analysis of

OPEN ACCESS

Edited by:

Manpreet Kaur Bagga,

Partap College of Education, India

Reviewed by: Jodi Nickel, Mount Royal University,

Canada Laura Sara Agrati,

University of Bergamo, Italy

*Correspondence: Yang Gao

gaoyang666@dlmu.edu.cn

Specialty section:

This article was submitted to

Teacher Education,

a section of the journal

Frontiers in Education

Received: 11 May 2021

Accepted: 21 July 2021

Published: 06 August 2021

Citation:

Gao $Y$ and Zhou Y (2021) Exploring

Language Teachers' Beliefs About the

Medium of Instruction and Actual

Practices Using Complex Dynamic

System Theory.

Front. Educ. 6:708031.

doi: 10.3389/feduc.2021.708031 interviews and classroom observations represented the tensions and changes between teacher beliefs and practices about the medium of instruction. The study calls for attention to the socially situated and co-evolving relations between teacher beliefs and practices and how they develop with contextual affordances, attractor states, flexible goals, and high dependence on initial conditions.

Keywords: teacher beliefs, teacher practices, complex dynamic systems theory, medium of instruction, case study

\section{INTRODUCTION}

Studies on language teacher beliefs have been carried out through various methods and tools for decades (Borg, 2003; Gao, 2014). Particularly, scholars are interested in understanding teacher beliefs, the relationship between teacher beliefs and teaching practices, the factors influencing teacher beliefs, and its connections with teacher development (Jackson, 1968; Clark and Peterson, 1986; Gao, 2014; Xiang, et al., 2016). The relationship between teacher beliefs and practices has received critical attention and thus has become an increasingly important area in applied linguistics. While it is widely believed that teacher beliefs are a complex and dynamic system, it can be difficult to study this kind of complexity and dynamism due to methodological or contextual challenges. Contributing to existing literature, this study explores how teacher beliefs about the medium of instruction may inform teacher practices in a complex manner.

\section{Background of the Research}

One of the research foci in teaching beliefs is the complex and dynamic relationship between teachers' beliefs and actions (Xiang, et al., 2016; Xiong, 2019). For decades, scholars held different views on the relationship between teachers' thoughts and actions in classes. Considerable studies have proposed that teachers' beliefs determined their classroom actions (Rupley and Logan, 1984; Richardson, et al., 1991), whereas other research has found little connection between teacher beliefs 
and practices (Basturkmen, 2012). Since then, there has been a fierce controversy between scholars who believed in the consistency between teachers' beliefs and practices and those who advocate the disparity between teachers' thoughts and actions. Naturally, to reconcile different points of view between the two schools, others found the co-existence of consistency and inconsistency between teaching beliefs and practices (Fang, 1996; Gao and Liu, 2013), which fully demonstrated the complex connections between teachers' beliefs and practices in classrooms.

In response to Piaget's cognition and development perspectives and the sociocultural theory of Vygotsky, social cognitive theory has gradually been put into practice in classrooms, and teacher beliefs are thus regarded as mediators of learner or teacher actions (Navarro and Thornton, 2011). Researchers following the trend began to shift their attention from teacher behavior to teacher cognition and explore teachers' psychology and cognitive world. Vast empirical studies in teacher beliefs were conducted to explore the interaction between teachers' beliefs and thoughts (Pajares, 1992; Freeman, 2002). This sociocultural perspective provided a theoretical framework, emphasizing the impact of teachers' background, experience, and participation in their cognition development and highlighting teachers' subjectivity. Although the sociocultural perspective took both individuals and environment into account, studies of such aspects often perceive teacher beliefs to be static and the relationship between beliefs and practices as linear.

\section{Research Objectives and Significance}

The purpose of this investigation is to explore the relationship between teachers' beliefs and teaching practices relating to the medium of instruction, especially from the perspective of Complex Dynamic Systems Theory (CDST). This study contributes to studies on CDST by demonstrating the relations between teachers' beliefs and practices about the medium of instruction in the classroom. The importance and originality of this study are rooted in its interdisciplinary application of CDST and new insights into existing applied linguistics studies.

As teacher beliefs study is an essential component of language teacher cognition research, the studies focusing on the relationship between teacher beliefs and teacher practices have gradually become an independent branch. Furthermore, with the veering direction of applied linguistics studies, regarding language as a complex and dynamic system, treating the relationship between teacher beliefs and practices as complex and dynamic has gradually been accepted by more and more researchers. However, although extensive research has been carried out to describe the connections between teaching beliefs and practices, few empirical investigations have been conducted that examine the complex and dynamic relationship. Thus, there is an urgent need to systematically analyze the connections between teacher beliefs and practices from the perspective of CDST.

\section{Research Questions}

This study aims to describe the complex and dynamic relationship between teacher beliefs and practices, especially the divergence between teacher opinions and actions about the functions of the medium of instruction. It will address the following two questions, which are essential to the tensions between teacher beliefs and practices:

1. What are the beliefs of Chinese EFL teachers concerning the medium of instruction, in terms of the modes and functions? Then, what are the teachers' actual practices in using the medium of instruction?

2. Are there any tensions between teachers' beliefs about the medium of instruction and their actual practices? If so, in what ways do beliefs inform the actual practices?

\section{LITERATURE REVIEW}

The relationship between teacher beliefs and teacher practices has been studied from different angles and researchers have constantly overturned and reestablished theories to better describe such relationships. Various paradigms have been employed to describe and analyze the relationship between teacher beliefs and practices with their ongoing efforts. In the wake of the development of research paradigms, scholars tried to delve into the subtle divergence and convergence between teacher beliefs and practices in terms of teaching subjects. As the deficiency in former theories grew distinct, the need to perceive the complexity of teacher beliefs and practices as dynamic systems has become urgent.

\section{Previous Studies on Teacher Beliefs and Practices}

Over the past 50 years, studies on the relationship between teacher beliefs and practices have been carried out through various paradigms, including positivism, constructivism, transformativism to pragmatism (Gao, 2014). The quantitative method-based positivism suggested that the relationship between teacher beliefs and practices was unidirectional. Phillip Jackson (1968) described and analyzed teachers' thoughts and cognition in Life in Classroom, supposing that thoughts determined teachers' actions. This book attracted the attention of education researchers, and teacher mental processes received attention. Until the early 1980s, extensive studies explored how the beliefs of teachers affected practices in the classroom. Research mostly supported the consistent relation between teacher beliefs and practices. Brown $(1962 ; 1963 ; 1966 ; 1968)$ continuously wrote papers to describe the coherence between teacher thoughts and practices. Similar consistency was found in the papers of Harvey et al., 1964; Harvey et al., 1965, Combs (1969), and the National Institute of Education (1975). Especially in the empirical studies of literacy education, Harste and Burke (1977) discussed the possibility of the leadership of teachers' beliefs in monitoring students' behavior and making classroom decisions. Many scholars in this period found the impact of teachers' different writing beliefs on classroom instruction (Mangano and Allen, 1986; Wing, 1989).

Constructivism emphasizes the learning process instead of the learning product, regarding classroom practices as a whole 
(Pressley, 2006). This theory represents the shift of studies around teacher beliefs and practices from one dimension to dual dimensions. Scholars began to suspect the authenticity of data about teachers' beliefs due to different research methods, the invalidity of which was approved in later studies. Basturkmen (2012) claimed that even complicated methods might be unable to elucidate the connections between teachers' beliefs and practices. During this period, innumerable studies attempted to extract data from teacher beliefs using different methodologies, such as policy capturing and process tracing. Nevertheless, these audacious experiments led to various criticisms about their inadequacy in revealing the authentic features of classrooms and explicit teachers' beliefs (Nisbett and Wilson, 1977; Clark and Peterson, 1986).

As an approach, pragmatism has advocated the exploration of this mixture of perspectives and methods. This approach acknowledges that contrary propositions do coexist and that these conflicting views, attitudes, and stances are nevertheless helpful in exploring research questions (Tashakkori and Teddlie, 2003). Pragmatism aggregates quantitative and qualitative methods to describe the complex relations between teacher beliefs and practices, as long as the technique met the demand of the analysis. As sociocultural theory has developed, and become more and more popular in education research, extensive studies have proved the impact of teachers on classroom practices. Furthermore, Barcelos and Kalaja (2011) outline that studies have gradually divided opinions into stable and variable ones and focus on the change and interaction between beliefs and practices from a systematic perspective.

\section{Previous Studies on Teacher Beliefs and Practices About the Medium of Instruction}

To date, most studies on teachers' beliefs and practices have focused on specific aspects of language teaching, such as grammar (Borg, 1998; Farrell and Lim, 2005; Phipps and Borg, 2009), speaking (Li and Shi, 2011), listening (Gao and Liu, 2013), writing (Cumming, 1992; Burns, 1992; Shi and Cumming, 1995; Yang, 2010; Yang and Gao, 2013), reflective teaching (Meng, 2011), multimedia teaching (Zhang and Zheng, 2011), and so on.

In grammar teaching, Gao and Liu (2008) concluded that teachers' beliefs were partly consistent with practices due to many inflectional factors by summarising relevant international studies. To describe the relationship between teacher beliefs and practices in the Chinese specialized language teaching environment, Gao and Qin (2010) combined qualitative and quantitative analytical methods to explore the relations between 396 teachers' beliefs and practices in grammar teaching, especially for non-English-major students in the university. In oral English teaching, Li and Shi (2011) investigated two college English teachers' beliefs and practices in an agricultural university. In terms of teaching listening, Gao and Liu (2013) collected 325 questionnaires for college English teachers and conducted case studies on four teachers towards non-English-major students. When examining the teaching of writing, Yang (2010) tracked three college English writing teachers teaching English-major students for a year by collecting classroom observations, semi-structured interviews, and teaching literature. Yang and Gao (2013) examined four experienced teachers' beliefs and practices in teaching English as a foreign language (EFL) writing at a university in China over two semesters with class observations, interviews, and course materials. Together these studies provided important insights into the consistency and inconsistency of teachers' beliefs and practices from the specific perspective of language teaching. However, there has been little discussion about teachers' beliefs and practices about the medium of instruction.

\section{Theoretical Framework: Complex Dynamic Systems Theory}

The development of research paradigms indicates that researchers have recognized the complexity and dynamism embedded in the relations between teachers' beliefs and practices, striving to break the shackles of unidirectional or interdependent relations. Complex Dynamic Systems Theory (CDST) is a method of systematically describing and analyzing the relationship between teachers' beliefs and practices about the medium of instruction.

CDST, which combines Complexity System and Dynamic Systems Theory, is a popular approach to studying second language acquisition. Complexity or Chaos science focuses on complex, active, and non-linear systems, meaning a process of becoming instead of being (Larsen-Freeman, 1997). Dynamic Systems Theory is used initially to describe simple systems such as two coupled variables in a double pendulum in mathematics. Despite only two variables, the system is too complex to trace (de Bot, et al., 2007). When applied to language development, CDST regards language as a complex, dynamic, and systematic system (Zheng, 2019).

CDST is chaotic, unpredictable, and sensitive to initial conditions. Chaos is an irregular and unpredictable situation when complex and dynamic systems interact and participate randomly. The unpredictability derives from the sensitive dependence of systems on initial states, as even a subtle modification of initial conditions could lead to substantial divergence in the future (Larsen-Freeman, 1997).

CDST is open, self-organizing, feedback sensitive, and adaptive. As exterior energy is available to systems, the complexity develops with obtaining power from the environment. Furthermore, the non-linear system would keep interacting with the environment if it opens to the constant external energy. According to Kauffman and Johnsen (1991), it is an inherent ability to select and self-organize be adaptive to complex systems. Systems take an active stance towards feedback and turn things in their favor.

CDST has strange attractors and demonstrates a fractal shape. An attractor is a tractable path that a dynamic system presents, like the orbit of a frictionless pendulum defined by two extremes at either end. The attractor is strange because all cycles are different from each other, and it is impossible to identify precisely where the system will be. Such a strange attractor can be described as 'stochastic behavior occurring within a deterministic system' (Larsen-Freeman, 1997). 
The principle and methodology of CDST provides a new method of analyzing the conundrums of applied linguistics. Scholars have started to use CDST to depict the relationship between teachers' beliefs and practices (Xiong, 2019; Yu, et al., 2020). Yu et al. (2020) explored two Macau novice secondary teachers' beliefs and practices about writing from the perspective of complexity theory through classroom observations, interviews, and pedagogical documents. They found that while teachers could keep the consistency between their beliefs and practices, there were still divergences due to different curricula and school policies. This study proved that CDST is an appropriate perspective to describe and analyze the relationship between teachers' beliefs and practices in classes.

\section{RESEARCH METHODOLOGY}

This empirical study collected data from interviews and classroom observations, combined quantitative and qualitative analytical models, and described the relationship between teacher beliefs and practices within a functional framework of classroom discourse.

\section{Participants and Context}

Table 1 presents the participant biographic information. Participants in the study include three teachers in a typical research-based university in northeast China, whose teaching experience ranged from 4 to 20 years. Participants were selected based on the researcher's previous experience as a student in classes, and all teachers are native Chinese speakers with learning experience. To explore the multiple dimensions of teacher beliefs as comprehensively as possible, each participant taught a different subject. Teachers respectively taught thesis writing, advanced interpretation, and French as the second foreign language of students. The language used in classes was not confined to the native language, Chinese, English, or other foreign languages. All teachers taught English major students who had received at least 6 years of English education before entering university.

\section{Research Design}

A case study is a useful way of analyzing research relevant circumstances exhaustively and describing social phenomenon extensively (Yin, 2014). This study requires an in-depth description of both teachers' beliefs and practices to explore the relationship between teacher thoughts and practices. Firstly, we collected and characterized teachers' views through semi-structured interviews. Then, we transcribed, edited, and coded recordings for analyzing the functions of classroom discourse according to the same functional framework of classroom discourse analysis.

\section{Data Collection and Analysis}

Data were collected from classes and semi-structured interviews. Having secured teachers' permission in advance, the three courses taught by each participant were recorded. Teachers were not informed of the purpose of the research. The second data resource were gathered through three semi-structured interviews. A semistructured interview was used to create an opportunity for teachers to speak freely about their opinions. Interviews were conducted in Chinese, and each teacher was given a code name (T1-T3) to preserve anonymity. Rather than asking questions about actual classroom discourse, questions at the beginning focused on teachers' thoughts and experiences on the course, students, and language. Before undertaking the interview, analysis and a rough conclusion of teacher practices were obtained from classroom recordings. The remainder of the interviews focused on the differences between the disclosed beliefs and the practices analyzed from recordings. The data were coded by three students and then compared with the percentage of each code within the group to minimize the effect of individual orientation.

\section{Analytical Framework}

Kang and Cheng (2011) reclassified the functions of foreign language teachers' classroom discourse by analyzing 15 classes of middle school English teachers by summarizing Interaction Analysis (Flanders, 1970; Moskowitz, 1971) and Discourse Analysis (Sinclair and Coulthard, 1975). The categories of Interaction Analysis were mainly based on speech that was perceptible in classes but always considered the mixed forms and functions of discourse due to a lack of consistency. The inherent flexibility and diversity of classroom discourse make it difficult to create any fixed classifications. Besides, this system separates classroom interaction into independent parts, overlooking its organic relations. Although discourse analysis emphasizes the integrity of classroom discourse, it neglects the environmental factors in which classroom discourse happens. Researchers believe that teachers have absolute authority in Initiation-Response-Follow-up (IRF) classrooms, which is so divergent from advocated student-oriented classrooms that it does not reflect the characteristics of classroom discourse (Kang and Cheng, 2011). Classroom discourse does not consist of full IRF mode. For instance, sometimes a response from students is unnecessary during activities and introductory sessions, which may also lack evaluation or follow-up from teachers. It is challenging to discover the fundamental pedagogical purposes and effects according to IRF mode.

Based on analyzing and coding discourse from traditional analyses, Kang and Cheng found that an avalanche of addresses

\begin{tabular}{|c|c|c|c|c|}
\hline Participants & Gender & Education & Teaching experience (Year) & Courses \\
\hline $\mathrm{T} 1$ & Male & Ph.D. U.S. & 14 & Thesis Writing \\
\hline T2 & Female & Ph.D. China & 3 & Advanced Interpretation \\
\hline T3 & Female & Master's Degree China & 32 & French as the Second Foreign Language \\
\hline
\end{tabular}


could not be classified. Compared with conventional teacheroriented classes, three teachers in that study preferred studentoriented styles with equal teacher-student relations and more negotiation in classroom interaction. Considering the forms and functions of discourse and its pedagogical functions, Kang and Cheng distinguished four macro and 25 micro functions of classroom discourse in the framework of classroom discourse functions. While macro-functions refer to pedagogical purpose, micro-functions involve forms and functions of speech in interaction. Macro-functions consist of language input, knowledge explanation, teacher-student interaction, event organization, classroom management, and social interaction. Each function could be judged according to its specific forms of discourse in classrooms (Kang and Cheng, 2011).

Language input function includes providing examples and making use of the students' utterances to provide foreign language input. Knowledge explanation is the direct interpretation of language, textbooks, cultural background, or other relevant information. Teacher-student interaction includes initiator, guidance, prompt, transformed questions, recognition, comment, direct correction, corrective feedback, evaluation, expansion, clarification request, and confirmation check. Event organization includes pre-instruction to introduce purpose, requirement, and regulation of activities, instruction, nomination, call, encouragement, and summary. Classroom management includes talking turn, comprehension verification, and discipline maintenance. Social interaction means the conversation that keeps or initiates interpersonal communication (Kang and Cheng, 2011).

Even though the framework of classroom discourse functions proposed by Kang and Cheng (2011) have not been used widely in research, they provide a way to analyze teachers' views about the medium of instruction and their classroom practices. As this study focuses on teachers' beliefs and practices, the pedagogical functions of classroom discourse should be considered. Similarly, the thoughts should be explored around teachers' understandings of the function of the medium of instruction.

\section{Exemplar Coding Excerpts}

The following examples from data analysis may exemplify the coding process in this study to present how the data from classroom observations and interviews were coded according to the same framework of classroom discourse functions.

This morning, the teacher took the time to listen to a lecture. But unfortunately, the lecture did not go so well, because it was delivered by a scholar abroad in the United States. (T2)

What T2 said in the class was not related to the subject, advanced interpreting, so this communication unit was coded into social interaction function according to the framework of classroom discourse functions.

(I would be happy to hear your good news at any time if you'd like to share...) All right, today we are going to have a presentation. (T2)

At times, one sentence functioned in two ways. The cited sentence above not only managed classroom talk turns ("all right") but also organized events by introducing the following activities. Naturally, this sentence was coded into classroom management and event organization functions.

At the beginning of the course, I wanted to remind the students of the importance of sensitive awareness of the news. [...] So let's talk to you a little bit about this first, one is to build up your awareness, another is to make you less nervous, and then transition to the next training. (T2)

What $\mathrm{T} 2$ expressed in interviews about the function of the medium of instruction as social interaction made clear that she was strongly convinced of the importance of social interaction in classes.

\section{FINDINGS}

Through quantitative and qualitative analysis of data from interviews and classroom observations, the complexity and dynamism of teacher beliefs and practices were detected in different beliefs towards MOI, divergent classroom practices, and tensions or even the changes between beliefs and practices.

\section{The Complexity of Teacher Beliefs and Practices}

Complexity existed in the teachers' opinions of the medium of instruction and their actual practices. Participants showed different views about using the medium of instruction in their classes in interviews and performed various functions of the medium of instruction in classrooms. (please refer to Table 2).

\begin{tabular}{|c|c|c|c|c|c|c|}
\hline Participants & Language input & $\begin{array}{l}\text { Knowledge } \\
\text { explanation }\end{array}$ & $\begin{array}{l}\text { Teacher-student } \\
\text { interaction }\end{array}$ & $\begin{array}{c}\text { Event } \\
\text { organization }\end{array}$ & $\begin{array}{c}\text { Classroom } \\
\text { management }\end{array}$ & $\begin{array}{c}\text { Social } \\
\text { interaction }\end{array}$ \\
\hline T1 & & $\sqrt{ }$ & & $\sqrt{ }$ & & $\sqrt{ }$ \\
\hline T2 & $\sqrt{ }$ & $\sqrt{ }$ & $\sqrt{ }$ & $\sqrt{ }$ & & $\sqrt{ }$ \\
\hline T3 & $\sqrt{ }$ & $\sqrt{ }$ & $\sqrt{ }$ & $\sqrt{ }$ & & $\sqrt{ }$ \\
\hline
\end{tabular}

Note. $\sqrt{ }$ refers to the existence of such function of $\mathrm{MOI}$ in teacher beliefs from analysis of interviews, while blank means the opposite situation for teacher beliefs. 


\section{Different Teachers Holding Different Beliefs About MOI}

Teachers claimed that the medium of instruction should provide students with knowledge explanation, event organization, and social interaction, apart from class management. Nevertheless, they differed in views towards the function of the medium of instruction as an instrument for language input and teacher-student interaction.

On the one hand, two participants expressed their willingness to provide language input in foreign languages in interviews, while one teacher favored the native language. T1 preferred the native language in teaching advanced subjects to make things clear. Meanwhile, T1 advocated the choice of the medium of instruction according to classes and grades. On the contrary, T2 claimed that more foreign language input would be suitable for students. Still, the teacher emphasized that teachers should pay attention to simpler vocabulary, sentence patterns, and so on, thus providing an environment where learners could comprehend instead of being confounded. Similarly, T3 also acknowledged the necessity of creating a foreign language environment that helped pave the way for advanced language skill learning and practice learners' grammar ability.

According to the curriculum and the grades, these are the medium of the language. [...] For teaching advanced courses. [...] In this case, I think it would be better if I explain it clearly in Chinese rather than in English [...]. (T1)

It would be better to have more English immersion and input. [...] All in English, it may also depend on the teacher whether you can change different levels of expressions (for students to understand) [...]. Only in this way can our students obtain knowledge from classes [...]. (T2)

I think it's a good idea to train students in such French skills so that they can improve their language [...]. To communicate with students in French, I think it's good to offer students access to the French environment to improve their language skills [...]. The grammar point [...]. (T3)

On the other hand, participants differed in their beliefs about the medium of instruction functioning as teacher-student interaction. T1 asserted that whether the medium of instruction functioned as an interaction instrument between teachers and students depended on the characteristics and duration of classes, believing this kind of interaction was essential for training specific language skills. The other two teachers held opposite beliefs that teacher-student exchange should have a place in classrooms. T2 was inclined to encourage the student with general comments first and then praise intelligent points in the answers from students. Based on giving feedback in teacher-student interaction, T3 advocated that teacher-student interaction should stress the importance of student-initiated communication and the drive of students' performance.

The classes of lower grades require interaction to stimulate them to practice a certain skill, but this class is not designed to stimulate students repeatedly [...]. (T1)

In fact, I would give a more general assessment beforehand, and then I would take a close look at the brilliant points of the response [...]. It's generally encouraging (comments) [...]. (T2)

I would make efforts to engage students in speaking [...]. Also, let the students have opportunities to perform [...]. This is because the conversations are in French and the students' interactions are in French [...]. (T3)

\section{The Practices Serving Different Functions}

Table 3 presents the results obtained from the preliminary analysis of classroom observations. From the table above, T1 focused on knowledge explanation, which occupied the classroom discourse more than half. In T1's classes, the most striking aspect of the data was the nearly deserted functions, including language input, classroom management, and social interaction. Compared with T1, T2 tended to spend more time on interaction with students and then knowledge explanation. Interestingly, social interaction and classroom management similarly accounted for less in T2's classes. Distinctively, in T3's classes, time was comparably distributed equally to language input, knowledge explanation, and event organization. This was a somewhat surprising outcome that social interaction accounted for not that small, rating still the last among six functions.

\section{Dynamism of Teacher Beliefs and Practices}

Dynamism hides in the discordant beliefs and practices about the medium of instruction in its function. Both conscious adjustments

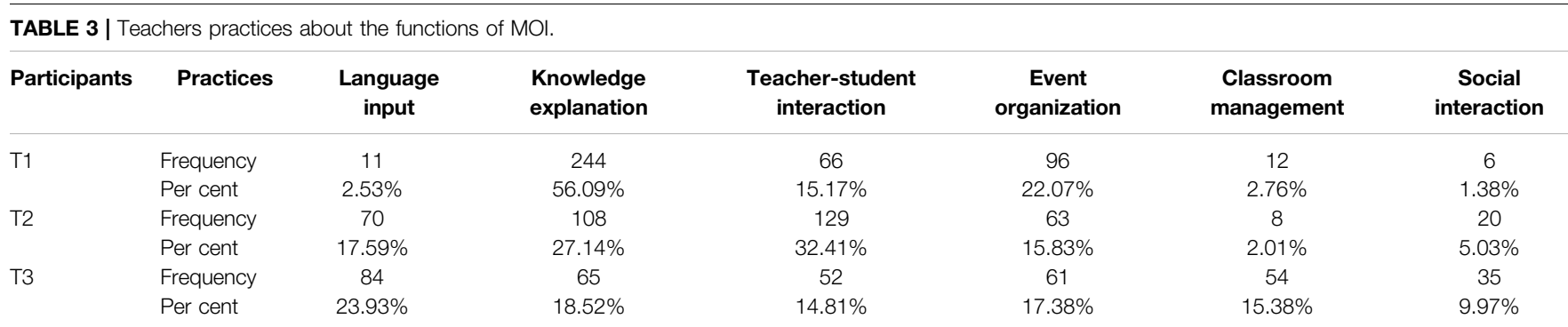


to students' instant response and unconscious adjustments due to unintentional teaching habits made in classrooms present divergences between teachers' beliefs and practices.

\section{Tensions Between Beliefs and Practices}

It is interesting to note that no teachers' beliefs could perfectly match their practices in all three cases of this study. First of all, teachers' beliefs mainly were reflected in classroom discourse in terms of the function of knowledge explanation and language input.

Teachers unanimously reached a consensus that knowledge explanation function should be viewed as an essential part of the medium of instruction and simultaneously achieved consistency between their beliefs and practices. T1 put the clarification of materials first, regardless of language restrictions, and consciously adjusted the medium of instruction to better explain knowledge for students. Similarly, T2 agreed to clarify professional language skills with more explanation to help learners have a comprehensive understanding of materials. T3 highlighted the necessity of explaining in the native language or other learned languages to learn a foreign language. Meanwhile, T3 adjusted the medium of instruction flexibly following different classroom contents and mobilized various ways of clarifying materials, including blackboard writing, vivid personal experiences, and connection with similar languages. The function of knowledge explanation rated highly among the six functions in analyzing all three teachers' practices.

If I have to be restricted by the language, then I think the students will be confused, so it is better for me to speak Chinese so that they can understand my lesson more clearly [...]. (T1)

If I think some students are confused, then I will explain it in Chinese so that you can understand it more thoroughly [...]. (T2)

Now at the foundation stage, it is necessary to teach in mother tongue [...]. I have to take into account even the weakest students. So I would end up having to make up for it; I might need to make up for it by writing on the board or by translating into Chinese to develop their French [...]. (T3)

Besides knowledge explanation, teachers also showed consistency in their beliefs and practices about the medium of function in language input. As mentioned in 4.1.1, T1 chose the native language instead of English to help students understand more easily, while the other two participants adherent to the use of the foreign language to provide a different language environment, under the pretext of comprehensive input. Surprisingly, the results obtained from classroom observations also supported these beliefs. The function of language input rated low in the case of T1 but ranked high in the other teachers' classes. In a word, language input and knowledge explanation represented the consistency between teachers' beliefs and practices about the function of the medium of instruction.
On the contrary, every participant showed one or two divergences between teaching beliefs and practices, especially in the declining percentage of functions from teachers' beliefs to practices. For one, all three teachers revealed inconsistency in terms of social interaction function. T1 revealed their eagerness to share and converse with students about experiences indirectly correlated to the classes regarding social interaction. T2 believed that social interaction was beneficial to enhance student's awareness of the situation of the international community and reduce their anxiety as a transitional instrument. T3 thought that they could use social interaction as a tool to provide vivid examples for students to practice grammar.

I think there are some [...]. Speaking of how I continued my studies of this major from undergraduate, graduate, to doctoral phrase [...]. (T1) In fact, in the beginning, it was a warm-up [...]. It is to encourage you to have an awareness of the news [...]. I think this should be a basic quality for students of humanities and social sciences, right? (T2)

I think that the advantage of this is that when I talk about grammar, my examples are not from grammar books; they are my own examples [...]. (T3)

From the analysis of interviews with participants, there was a common recognition of the critical role of the medium of instruction functioning as social interaction. By contrast, the function of social interaction was rated last in all three teachers' practices. The falling status of the function of social interaction from teachers' beliefs in classrooms exemplified the tensions between teaching thoughts and practices.

The respectively lower status of the function of event organization and teacher-student interaction in the two participants' practices also revealed tensions between teachers' beliefs and practices. T2 admitted that the importance of engagement for every student in classrooms and tried to enhance participation in each class. T3 claimed that teacher-student interaction played an important role in student-oriented interaction and performance as mentioned in 4.1.1, and in enhancing their ability to make typical and useful sentences in French.

I do try to give everyone a chance to practice, I guess since they come [...]. Get some exercise, so I try to call on every student [...]. (T2)

In fact, I still help students to practice the ability to make sentences, that is, the ability to turn words into sentences. They have to practice making sentences, especially typical expressions in French [...]. (T3)

In stark contrast to teachers' firm beliefs in the importance of event organization and teacher-student interaction, the two functions in their classroom practices held relatively low status compared with other functions. From the data on classroom observations, event organization ranked fourth among the six functions of the medium of instruction for T2 and teacher- 
student interaction held the same inferior rank in T3 practices about the medium of instruction.

\section{Changes in Beliefs and Practices}

After describing the consistency and inconsistency between teachers' beliefs and practices about the function of the medium of instruction from interviews and classroom observations, the changes that emerged in classrooms are required to better exemplify the dynamism in teachers' beliefs and practices. While tensions between beliefs and practices mainly refer to the imbalanced reflection of the function of the medium of instruction in teachers' beliefs and practices, changes between the two refer to the sudden appearances in classes in terms of the function of the medium of instruction, which had no status in teachers' beliefs from interviews.

Systematically speaking, two participants both presented changes in their beliefs and practices respectively in the function of the medium of instruction in teacher-student interaction and classroom management. T1 fully exemplified the variation in teaching beliefs and practices. When it comes to teacher-student interaction, $\mathrm{T} 1$ asserted that the medium of instruction functioning as teacher-student interaction mattered less than other functions due to the restrictions on the nature of the subject; however, in practice, teacher-student interaction rated third, holding a strong position compared with the consistent functions of the medium of instruction in teachers' beliefs and practices (see Table 3 ).

In terms of volume, I don't think my course is particularly interactive due to the nature of the course and the length of the course, but my class is not designed to stimulate you repeatedly, so that's why it's relatively less interactive [...]. (T1)

Likewise, T3 presented an unsuccessful switch in the function of classroom management between teaching opinions and actions. In interviews, T3 believed that talk uncorrelated to classes and social interaction would take the place of classroom management in appealing to students instead of governing them directly. The participant was also reluctant to enforce discipline on students for better class regulation. Nevertheless, the function of direct classroom management still occupied a relatively large proportion of teacher practices in classrooms, apart from the initial willingness to make use of social interaction as a means of managing students.

I think if a student is checking his phone down there, that's because I'm not engaging them, and they are looking at their phone [...]. I realized that I'm monotonous, I have to adjust, this is when I might come in with gossip [...]. (T3)

$\mathrm{T} 1$ subjectively considered that the function of teacher-student interaction had nothing to do with the quality of the classes, while the intercommunication between participants and students ranked third among six functions of the medium of instruction. Similarly, interviews with T3 made clear that T3 planned to replace straightforward regulation with engaging daily news, whereas classroom observations of $\mathrm{T} 3$ reflected the extensive employment of explicit classroom management as a function of the medium of instruction. No matter which category the function falls into, the comparison between lack of awareness in teachers' beliefs and strong position in classrooms, indicates differences between teachers' opinions and their actions in terms of how the medium of instruction functions.

\section{DISCUSSION}

Whilst it is significant that all three teachers were in charge of totally different classes and that they had varied experiences of teaching, the analysis of interviews and observations indicates the complexity and dynamism embedded in the relations between teachers' beliefs and practices.

\section{Socially Located, Co-Evolving, and Externally Interactive Beliefs and Practices}

Beliefs and practices are socially situated, co-evolving, and require contextual adaptation. Firstly, the findings of this study provide further evidence of the mutual interaction between teachers' beliefs and practices. Thoughts originate from the environment where the teachers practice and live, and are limited to the values and culture of the environment and influence teachers' practices. Teachers aim in turn to improve their beliefs through reflective and accumulative experience after classroom practices (Jin and Ma, 2013). Teachers' beliefs and practices are socially situated, since teachers want to equip students with an international world view through social and teacher-student interaction, believing in the significance of being a person with humanistic quality in the future. Pajares (1992) found that the formation of teachers' beliefs was mainly influenced by social culture and personal learning experience, which implicitly affected personal views towards education, teaching, learning, teachers and students roles, and educational questions in the process of socialization. This study attested to Pajares' findings by revealing teachers' dependence on their reflective thoughts on receiving education. Furthermore, teachers could consciously improve, even change their teaching methods after learning from their experience as learners, innovate pedagogical practices to enhance effectiveness, and adapt to the ever-changing social culture.

The co-evolving relations between teachers' beliefs and practices manifest themselves in teachers' willingness to receive outside opinions and instantly adjust the medium of instruction when students get bored or respond in unexpected ways. Consistent with other second language classrooms, mutual adaptation was the most dynamic element (Cameron and LarsenFreeman., 2008). The three teachers were eager to hear different voices from students, colleagues, and other observers, striving to perfect their use of functions of the medium of instruction in classrooms and systematize their understanding of the medium of instruction. More than one teacher asked for advice or took the initiative to adjust the medium of instruction after being informed of the inequality of their discourse distribution in different functions. Their positive response was unexpected but perfectly reflected that their beliefs systems were open and evolving all the time, regardless of the length of teaching experience and subjects. Teachers combined information from the outside environment and internal introspection to modify and improve their beliefs and practice systems. 
Meanwhile, contextual affordances are indispensable in teachers' beliefs and practices; for instance, different types of student responses could alter the mode of teacher-student interaction and event organization. The nature and duration of the curriculum could also affect the frequency and content of the interaction between teachers and students in beliefs and practices. Moreover, macro education policies could promote or inhibit teachers' beliefs and practices about the specific function of the medium of instruction. This confirms the assumption proposed by Zheng (2019), which mainly claims that the complete connectivity determined the high dependence between teachers' beliefs systems and practice systems. Whether the adjustment happened in a macro social environment or micro classroom context, it would lead to discrete changes in teachers' thoughts and behaviors in classrooms. In this study, all teachers claimed that institutional policies, such as the cut of class duration, greatly influenced teaching, causing divergences between teachers' beliefs and practices. Under such circumstances, teachers had to make trade-offs in selecting content and the arrangement of classroom sections, and so on: directly affecting the allocation of time in different functions of classroom discourse. Furthermore, educational policies at the national level could directly affect teachers' beliefs, requesting new materials should be taught to students and directly change the structure or content of each class.

In conclusion, teachers' beliefs and practices were cultivated and formed with the development of social culture, facing different views from outside and internal reflection, interacting closely and adjusting themselves according to contextual changes such as students' response, curriculum length, and policy levels.

\section{The Unpredictable Systems of Teacher Beliefs and Practices}

Initial condition, attractor states, and goals determine the complex, dynamic nature of teacher beliefs and practices. The second finding concerns the evolution of teachers' beliefs and practice systems, depending on the initial condition and settling down in attractor states under the influence of flexible goals. Zheng and Feng (2017) found that the interaction of syntactic and lexical systems is at a low level while the syntactic and linguistic systems of the written language of advanced learners are in an attractor state. The interaction of syntactic and lexical systems is at a higher level while intermediate and advanced learners make progress to a higher level. The consistency and inconsistency both are evidence of the development, disappearance, and emergence through the interaction of systems. The development of complex dynamic systems is a two-way evolution full of both progress and regression. Consequently, the belief and practice of teachers are not necessary to be constrained by improvement in a single aspect but should be encouraged to develop more dynamic, complex, and systematic systems.

The consistency of belief and practice systems may represent the attractor state, while the emergence of a repeller state might be inconsistent. The attractor state does not mean absolute correctness, and the repeller state is not a bad thing. The attractor state may reflect the dynamic balance that the multiple dimensions of belief and practice systems reach. The repeller state could provide an opportunity for teachers to develop themselves (Schmid, et al., 2013; Larsen-Freeman, 2017). The initial state of the relations between teachers' beliefs and practices may present as simple initially; however, beliefs and practice systems evolve unpredictably through complex and dynamic interconnection and self-organization. Attractor states are determined by various factors, including learners' response, institutional policies, national education promotion, and teachers' reflection, etc. These factors influence the interaction between teachers' beliefs and practices through teachers' instant or subsequent, active or passive adjustment. In this way, the initial conditions transform by absorbing energy from the exterior and interior materials.

The goals expressed in interviews can be reflected in practices but they can also be forgotten in practice in classrooms. On the one hand, to create an environment promoting international vision, teachers did fulfill the task by allocating more time to the function of social interaction in classes. On the other hand, although teachers planned to tell irrelevant stories in classes for managing students and creating an opportunity to practice grammar, this method of wielding the medium of instruction was not prominent in classroom discourse. In this process, the initial purposes were transformed and indirectly functioned for other objectives (Yang and Li, 2020). The dynamic goals represented in teachers' beliefs and practices depict divergences between interviews and classroom observations. All in all, the high level of sensitivity of beliefs and practices systems on initial conditions, the emergence of various attractor states in practices, reflection, and self-organisation, and both completed and unfinished goals in classrooms work together to determine the complexity and dynamism of teachers' beliefs and practices.

\section{CONCLUSION}

This study shows that the relation between teacher's beliefs and practices about MOI are complex and dynamic, which provides a new perspective for studies about the ties between teacher's beliefs and practices. Under the guidance of CDST, teacher's beliefs and practice systems are closely connected, with various factors interacting all the time. The complexity comes from the difference in the three teachers' beliefs about the proportion of functions of the medium of instruction and their disparate practices in applying the medium of instruction. Dynamism can be identified from the divergences between teachers' beliefs and practices relating to the medium of instruction in its functions.

From the perspective of CDST, a complex dynamic system is in evolution with stagnation in the attractor state and disorder in the repeller state (Zheng, 2019). Systems of beliefs and practices develop in the same way as consistency between beliefs and practice systems, which may represent the balance achieved through the interactions of various elements in belief systems, practice systems, and environment. Socially situated teachers' 
beliefs and practices depend on the contextual affordances of their co-evolving course. Adaptive goals and the other elements contributing to attractor states could trace the trajectory of teachers' beliefs and practice systems that are also highly sensitive to initial conditions.

There is an agreement that teachers' beliefs and practices are dynamic and complex, but relevant studies are scarce. Even though CDST has attracted more and more attention from applied linguistics, case studies are still scarce. Although this study has improved our understanding of the relations between teachers' beliefs and practices, it is limited by the absence of diachronic observation of teachers. Thus it is impossible for the survey to deeply follow the development of teachers' beliefs and practice systems, let alone analyze the reasons behind the occurrence of attractor and repeller states.

One source of weakness in this study that could have affected the measurement of teachers' practices is data analysis of classroom recordings. Compared with the detailed coding of interviews, the transcript of the recording was tackled in the communication unit, which means that the counting of each function could be less than actual classrooms. Nonetheless, the coding task would be more demanding if the classroom talk was divided into sentences, shattering the whole meaning conveyed in a sequence of sentences. Some sentences could be incomplete both in form and content. A better solution for data analysis could be to analyze the communication unit first then separating it into sentences, which might double the coding task.

This research has raised many questions, calling for future investigation. Further experimental studies are extremely needed

\section{REFERENCES}

Barcelos, A. M. F., and Kalaja, P. (2011). Introduction to Beliefs about SLA Revisited. System 39 (3), 281-289. doi:10.1016/j.system.2011.07.001

Basturkmen, H. (2012). Review of Research into the Correspondence between Language Teachers' Stated Beliefs and Practices. System 40 (2), 282-295. doi:10.1016/j.system.2012.05.001

Borg, S. (1998). Teachers' Pedagogical Systems and Grammar Teaching: A Qualitative Study. TESOL Q. 32 (1), 9-38. doi:10.2307/3587900

Brown, B. B. (1963). Acquisition versus Inquiry. Elem. Sch. J. 64 (1), 11-17. doi:10.1080/23808985.1979.1192378110.1086/460085

Brown, B. B. (1966). Bringing Philosophy into the Study of Teacher Effectiveness. J. Teach. Edu. 17 (1), 35-40. doi:10.1177/002248716601700105

Brown, B. B. (1969). Congruity of Student Teachers' Beliefs and Practices with Dewey's Philosophy. Educ. Forum 33 (2), 163-168. doi:10.1080/00131726909338830

Brown, B. B. (1962). The Relationship of Experimentalism to Classroom Practice. Madsion: Unpublished doctoral dissertation. University of Wisconsin. doi:10.1109/irenc.1962.199218

Burns, A. (1992). Teacher Beliefs and Their Influence on Classroom Practice. Prospect 7 (3), 56-66. https://search.informit.org/doi/10.3316/aeipt.66275.

Cameron, L., and Larsen-Freeman, D. (2008). Complex Systems and Applied Linguistics. Oxford, UK: Oxford Applied LinguisticsOxford University Press.

Clark, C. M., and Peterson, P. L. (1986). “Teachers' Thought Process,” in Handbook of Research in Teaching. Editor M. C. Wittrock (New York: Macmillan).

Combs, A. W. (1969). Florida Studies in the Helping Professions. Gainesville: University of Florida Press.

Cumming, A. (1992). Instructional Routines in ESL Composition Teaching: A Case Study of Three Teachers. J. Second Lang. Writing 1 (1), 17-35. doi:10.1016/ 1060-3743(92)90018-K to estimate the dynamic development route of teachers' beliefs and practices. It is helpful to discover triggers and analyze the general rules hidden in an active and complex development by following the growth tracks of teachers' thoughts and actions, as the experience and self-reflection of the teacher accumulates. Furthermore, more relevant studies should be carried out to explore the influential elements outside the teachers' beliefs and practices systems.

\section{DATA AVAILABILITY STATEMENT}

The raw data supporting the conclusions of this article will be made available by the authors upon request.

\section{ETHICS STATEMENT}

Ethical review and approval was not required for the study on human participants in accordance with the local legislation and institutional requirements. The patients/participants provided their written informed consent to participate in this study.

\section{AUTHOR CONTRIBUTIONS}

YG has contributed to the overall design, organization, and logic of the paper, YZ has contributed to the data collection and analysis of the paper. Both authors have contributed to the drafting and proofreading of the paper.

De Bot, K., Lowie, W., and Verspoor, M. (2007). A Dynamic Systems Theory Approach to Second Language Acquisition. Bilingualism 10 (1), 7. doi:10.1017/ S1366728906002732

Fang, Z. (1996). A Review of Research on Teacher Beliefs and Practices. Educ. Res. 38 (1), 47-65. doi:10.1080/0013188960380104

Farrell, T. S., and Lim, P. C. P. (2005). Conceptions of Grammar Teaching: A Case Study of Teachers' Beliefs and Classroom Practices. Tesl-Ej 9 (2), n2.

Flanders, N. A. (1970). Analyzing Teaching Behavior. Addison-Wesley. doi:10.2514/6.1970-696

Freeman, D. (2002). The Hidden Side of the Work: Teacher Knowledge and Learning to Teach. A Perspective from north American Educational Research on Teacher Education in English Language Teaching. Lta 35 (1), 1-13. doi: $10.1017 /$ S0261444801001720

Gao, Q., and Liu, L. (2013). Investigating College English Teacher Beliefs in Listening and Their Relationships with Teaching Practices. Foreign Lang. World 155 (02), 33-41.

Gao, Q., and Liu, Z. (2008). Teacher Cognition in Foreign Language Grammar Teaching. Foreign Lang. Learn. Theor. Pract. 122 (02), 62-67+54.

Gao, Q., and Qin, J. (2010). An Exploration of the Relationship between Grammar Teaching Beliefs Held by College EFL Teachers and Their Grammar Teaching Practices. Foreign Lang. Learn. Theor. Pract. 131 (03), 50-56.

Gao, Y. (2014). Language Teacher Beliefs and Practices: A Historical Review. J. English as Int. Lang. 9 (2), 40-56.

Harste, J. C., and Burke, C. L. (1977). "A New Hypothesis for reading Teacher Research: Both the Teaching and Learning of reading Is Theoretically Based," in Reading: Theory, Research and Practice. Editor P. D. Pearson (New York: National Research Conference).

Harvey, O. J. (1964). Some Cognitive Determinants of Influencibility. Sociometry 27 (2), 208-221. doi:10.2307/2785717 
Harvey, O. J. (1965). Some Situational and Cognitive Determinants of Dissonance Resolution. J. Personal. Soc. Psychol. 1 (4), 349-355. doi:10.1037/h0021873

Jackson, P. W. (1968). Life in the Classrooms. New York: Holt Rinehart \& Winston.

Jin, A., and Ma, Y. (2013). Research of the Foreign Teachers Beliefs under the Theory of Cultural Ecology. Mod. Edu. Manag. (04), 123-128. doi:10.16697/ j.cnki.xdjygl.2013.04.005

Kang, Y., and Cheng, X. (2011). A New Framework of the Functions of Foreign Language Teachers Classroom Discourse. Foreign Lang. Learn. Theor. Pract. 1 (03), 7-14.

Kauffman, S. A., and Johnsen, S. (1991). Coevolution to the Edge of Chaos: Coupled Fitness Landscapes, Poised States, and Coevolutionary Avalanches. J. Theor. Biol. 149 (4), 467-505. doi:10.1016/S0022-5193(05)80094-3

Larsen-Freeman, D. (1997). Chaos/complexity Science and Second Language Acquisition. Appl. Linguistics 18 (2), 141-165. doi:10.1093/applin/18.2.141

Larsen-Freeman, D. (2017). "Chapter 1. Complexity Theory," in Complexity Theory and Language Development: In Celebration of Diane LarsenFreeman. Editors L. Ortega and Z. Han (Amsterdam, Netherlands: John Benjamins), 11-50. doi:10.1075/lltt.48.02lar

Li, Y., and Shi, Y. (2011). Conceptions of Oral English Teaching: A Case Study of Teacher Cognition on Oral English Teaching and Classroom Practice. Chin. J. Appl. Linguistics 34 (01), 22-34+126.

Mangano, N., and Allen, J. (1986). Teachers' Beliefs about Language Arts and Their Effect on Student Beliefs and Instruction. Natl. Reading Conf. Yearb. 35, 135-142.

Meng, C. (2011). A Study of EFL Teachers' Reflective Teaching Perceptions and Practices in Chinese Universities. Foreign Lang. World 145 (04), 44-54.

Moskowitz, G. (1971). Interaction Analysis-A New Modern Language for Supervisors. Foreign Lang. Ann. 5 (2), 211-221. doi:10.1111/j.19449720.1971.tb00682.x

National Institute of Education (1975). "Teaching as Clinical Information Processing,". Report of Panel 6 (Washington, DC: National Conference on Studies of Teaching).

Navarro, D., and Thornton, K. (2011). Investigating the Relationship between Belief and Action in Self-Directed Language Learning. System 39 (3), 290-301. doi:10.1016/j.system.2011.07.002

Nisbett, R. E., and Wilson, T. D. (1977). Telling More Than We Can Know: Verbal Reports on Mental Processes. Psychol. Rev. 84 (3), 231-259. doi:10.1037/0033295X.84.3.231

Pajares, M. F. (1992). Teachers' Beliefs and Educational Research: Cleaning up a Messy Construct. Rev. Educ. Res. 62 (3), 307-332. doi:10.3102/00346543062003307

Phipps, S., and Borg, S. (2009). Exploring Tensions between Teachers' Grammar Teaching Beliefs and Practices. System 37 (3), 380-390. doi:10.1016/ j.system.2009.03.002

Pressley, M. (2006). Reading Instruction that Works: The Case for Balanced Teaching. New York: The Guilford Press. doi:10.1002/0470018860.s00678

Richardson, V., Anders, P., Tidwell, D., and Lloyd, C. (1991). The Relationship between Teachers' Beliefs and Practices in Reading Comprehension Instruction. Am. Educ. Res. J. 28 (3), 559-586. doi:10.3102/00028312028003559

Rupley, W. H., and Logan, J. W. (1985). Elementary Teachers' Beliefs about Reading and Knowledge of Reading Content: Relationships to Decision about Reading Outcomes. Reading Psychol. 6 (3-4), 145-156. doi:10.1080/ 0270271850060303

Schmid, M. S., Köpke, B., and De Bot, K. (2013). Language Attrition as a Complex, Non-linear Development. Int. J. Bilingualism 17 (6), 675-682. doi:10.1177/ 1367006912454619
Shi, L., and Cumming, A. (1995). Teachers' Conceptions of Second Language Writing Instruction: Five Case Studies. J. Second Lang. Writing 4 (2), 87-111. doi:10.1016/1060-3743(95)90002-0

Sinclair, J. M., and Coulthard, M. (1975). Towards an Analysis of Discourse: The English Used by Teachers and Pupils. Oxford: Oxford University Press.

Tashakkori, A., and Teddlie, C. (2003). Handbook of Mixed Methods in Social and Behavioral Research. Thousand Oaks, California: Sage.

Wing, L. A. (1989). The Influence of Preschool Teacher's Beliefs on Young Children's Conceptions of reading and Writing. Early Child. Res. Q. 4 (1), 61-74. doi:10.1016/S0885-2006(89)90077-X

Xiang, M., Zheng, X., and Wu, Y. (2016). Research on Language Teacher Beliefs: Review and Reflection. Foreign Lang. World 172 (01), 79-86+95.

Xiong, Y. (2019). Complexity Systems Theory: A Possible Perspective for the Study of EFL Teacher Belief. J. Curriculum Instruction 42 (02), 42-47.

Yang, L. (2010). Exploring Chinese university EFL Teachers Beliefs and Practices in Writing Instruction. Foreign Lang. Learn. Theor. Pract. 130 (02), 59-68.

Yang, L., and Gao, S. (2013). Beliefs and Practices of Chinese university Teachers in EFL Writing Instruction. Lang. Cult. Curriculum 26 (2), 128-145. doi:10.1080/ 07908318.2013 .794817

Yang, L., and Li, P. (2020). A Case Study on High School EFL Teachers Beliefs and Practices in Writing Instruction. Foreign Lang. Learn. Theor. Pract. 171 (03), 21-28.

Yin, R. K. (2014). Case Study Research Design and Methods. 5th ed.. Thousand Oaks, California: Sage.

Yu, S., Xu, H., Jiang, L., and Chan, I. K. I. (2020). Understanding Macau Novice Secondary Teachers' Beliefs and Practices of EFL Writing Instruction: A Complexity Theory Perspective. J. Second Lang. Writing 48, 100728. doi:10.1016/j.jslw.2020.100728

Zhang, Y., and Zheng, X. (2011). Exploration into Teachers Beliefs on Foreign Language Curriculum Integration with Information Technology. Foreign Lang. Edu. 32 (04), 52-56. doi:10.16362/ j.cnki.cn61-1023/h.2011.04.001

Zheng, Y., and Feng, Y. (2017). A Dynamic Systems Study on Chinese EFL Learners Syntactic and Lexical Complexity Development. Mod. Foreign Languages 40 (01), 57-68+146.

Zheng, Y. (2019). The CDST Perspective on Effective Foreign Language Teaching. Contemp. Foreign Languages Stud. 19 (05), 12-16+49.

Conflict of Interest: The authors declare that the research was conducted in the absence of any commercial or financial relationships that could be construed as a potential conflict of interest.

Publisher's Note: All claims expressed in this article are solely those of the authors and do not necessarily represent those of their affiliated organizations, or those of the publisher, the editors and the reviewers. Any product that may be evaluated in this article, or claim that may be made by its manufacturer, is not guaranteed or endorsed by the publisher.

Copyright (C) 2021 Gao and Zhou. This is an open-access article distributed under the terms of the Creative Commons Attribution License (CC BY). The use, distribution or reproduction in other forums is permitted, provided the original author $(s)$ and the copyright owner(s) are credited and that the original publication in this journal is cited, in accordance with accepted academic practice. No use, distribution or reproduction is permitted which does not comply with these terms. 


\section{APPENDIX INTERVIEW QUESTIONNAIRE}

1. What was your understanding of the language and the learning process? When you were an undergraduate, how did your teachers teach classes?

2. Which language do you think should be used to teach this course? Why? Would you say that you have used this language in the actual classroom?

3. Do you think we need to teach a course entirely in a foreign language? When do you think it would be better to use English? When do you think it would be better to use Chinese?

4. Under what circumstances do you adjust the ratio of the language of instruction (foreign languages to Chinese and vice versa) during the course of your lessons? (The researcher continued to ask questions or lead with prompts: different grades/different courses/different majors/different genders/ different urban backgrounds? What is your rationale for switching languages or adjusting the ratio?

5. Do you have any difficulties or challenges when teaching in a particular language? For example, in what areas? How did you solve these problems?

Based on the analysis of the transcribed documents from classrooms, the researcher continued to probe the above questions in terms of the relationship between teachers' beliefs and their practice. If beliefs and practice were inconsistent, the researcher would ask why they are inconsistent; if they are consistent, the researcher would continue to ask additional questions about the role and function of the pedagogical language in the examples from the analysis. 